\title{
Imaging in carcinoid heart disease
}

\author{
Mislav Klobučić ${ }^{1 *}$, Maja Hrabak Paar², Ranka Štern Padovan², Josip Vincelj ${ }^{3}$ \\ ${ }^{1}$ Bjelovar General Hospital, Bjelovar, Croatia \\ ${ }^{2}$ University Hospital Center Zagreb, Zagreb, Croatia \\ ${ }^{3}$ University Hospital Dubrava, Zagreb, Croatia
}

Carcinoid tumours are rare malignant tumours arising from the neural crest amine precursor uptake and decarboxylation cells, in particular from those situated in the gastrointestinal tract. These tumours are slow growing and indolent, but when they metastasise to the liver, their vasoactive products (5-hydroxytryptamine or serotonin, histamine, tachykinins etc.) which are regularly metabolised in the endothelium of the liver and lung vasculature, can reach the circulation and thereafter produce symptoms of carcinoid syndrome (CS), characterised by dermal flushing, diarrhoea, bronchospasm and valvular carcinoid heart disease (CHD). The latter is the most serious manifestation of CS, leading to heart failure and death in $40 \%$ of all affected. Cardiac lesions are a consequence of serotonin-induced deposition of fibrous tissue on the endocardial surfaces of the heart. They are mainly found in the right side of the heart and are truly pathognomonic. Although echocardiography is still the main imaging technique in the diagnosis and follow up of $\mathrm{CHD}$, in the last decade magnetic resonance imaging (MRI) has evolved into a promising new diagnostic modality. Most of the reported MRI features are similar to those observed by echocardiography - tricuspid and/or pulmonary valve thickening and immobility with consequent valvular dysfunction and right heart enlargement ${ }^{1-3}$. In our patient, endocardial enhancement of the right atrium and right ventricle including the endocardial surface of the subvalvular apparatus and both sides of the tricuspid valve was observed. We believe that this type of late enhancement corresponds with the wellknown histological features of CHD.

KEYWORDS: carcinoid heart disease, echocardiography, cardiac magnetic resonance imaging.

\section{Received: 20 2013}

*Address for correspondence: Opća bolnica Bjelovar, Mihanovićeva 8, HR-43000 Bjelovar, Croatia.

Phone: +385-43-279-222

E-mail: mislav.klobucic@bj.t-com.hr

\section{Literature}

1. Mollet NR, Dymarkowski S, Bogaert J. MRI and CT revealing carcinoid heart disease. Eur Radiol. 2003;13(Suppl 6): L14-L18.

2. Bastarrika G, Cao MG, Cano D, Barba J, de Buruaga JDS. Magnetic resonance imaging diagnosis of carcinoid heart disease. J Comput Assist Tomogr. 2005;29:756-9.

3. Franzen D, Boldt A, Raute-Kreinsen U, Koerfer R, Erdmann E. Magnetic resonance imaging of carcinoid heart disease. Clin Cardiol. 2009;32:E92—E93. 